\section{Fabrication and intracellular delivery of siRNA/carbonate apatite nano-composites for effective knockdown of cyclin B1 gene}

\author{
Anthony Stanislaus, ${ }^{1}$ Sharif Hossain, ${ }^{2}$ \\ Ming Jang Chua, ${ }^{1}$ Anil Philip Kunnath, ${ }^{1}$ \\ Quek Chia Wen, ${ }^{1}$ Sharifah Nur Syakira, ${ }^{1}$ \\ Gan Yew Siong, ${ }^{1}$ Siong Wei Loong, ${ }^{1}$ \\ lekhsan Othman, ${ }^{3}$ Toshihiro Akaike, ${ }^{2}$ \\ Ezharul Hoque Chowdhury ${ }^{3}$ \\ ${ }^{1}$ Faculty of Medicine and Health Science, \\ International Medical University (IMU), \\ Kuala Lumpur, Malaysia; ${ }^{2}$ Graduate \\ School of Bioscience and Biotechnology, \\ Tokyo Institute of Technology, Yokohama, \\ Japan; ${ }^{3}$ Jeffrey Cheah School of Medicine \\ and Health Sciences, Monash University \\ Sunway Campus, Jalan Lagoon, Selatan, \\ Bandar Sunway, Selangor Darul Ehsan, \\ Malaysia
}

\section{Abstract}

Gene therapy through intracellular delivery of a functional gene or a gene-silencing element is a promising approach to properly treat critical human diseases like cancer. The ability of synthetically designed small interfering RNA (siRNA) to effectively silence genes at post-transcriptional level has made them attractive options in targeted therapeutics. However, naked siRNA being unable to passively diffuse through cellular membranes, poses difficulty in fully exploiting the potentia of the technology. pH-sensitive carbonate apatite has been developed as an efficient tool to deliver siRNA into the mammalian cells by virtue of its high affinity interaction with the siRNA and effective cellular endocytosis. Moreover, internalized siRNA has been found to escape from the endosomes in a timedependent manner and effectively silenced reporter gene expression. Knockdown of cyclin $\mathrm{B} 1$ gene with only $10 \mathrm{nM}$ of siRNA delivered by carbonate apatite has resulted in significant death of cervical cancer cells. Moreover, delivery of siRNA against cyclin B1 gene has led to the sensitization of the cancer cells to both cisplatin and doxorubicin at a particulat drug concentration. Thus, the new method of siRNA delivery is highly promising for pre-clinical and clinical cancer therapy using siRNA therapeutics.
Correspondence: Ezharul Hoque Chowdhury, Jeffrey Cheah School of Medicine and Health Sciences, Monash University Sunway Campus, Jalan Lagoon, Selatan, Bandar Sunway, Selangor Darul Ehsan, Malaysia.

Tel. +603.5514.5628 - Fax: +603.5514.6323.

E-mail: ezharul_chowdhury@imu.edu.my

Key words: carbonate apatite, nanoparticles, siRNA, gene knockdown, cancer, cyclin B1, cisplatin, doxorubicin, paclitaxel.

Acknowledgements: this work has financially been supported by a research grant (Project ID 02-02-09-SF0013) of the Ministry of Science, Technology and Innovation (MOSTI), Malaysia.

Received for publication: 6 May 2011.

Revision received: 20 June 2011.

Accepted for publication: 23 June 2011.

This work is licensed under a Creative Commons Attribution NonCommercial 3.0 License (CC BYNC 3.0).

(C) Copyright A. Stanislaus et al., 2011

Licensee PAGEPress, Italy

Drugs and Therapy Studies 2011; 1:e8

doi:10.4081/dts.2011.e8 mid prior to the selection and verification of the active sequences ${ }^{7}$ and the requirement of the plasmid to cross the nuclear membrane for shRNA expression. ${ }^{8}$ The ability of siRNA to potently, but reversibly, silence genes in vivo has made them a highly promising drug therapeutic with several different clinical trials ongoing and more poised to enter the clinic. ${ }^{2,5}$ However, because of the strong anionic phosphate backbone with consequential electrostatic repulsion from the anionic cell membrane, siRNA is unable to passively diffuse across the membrane. ${ }^{9}$ For intracellular delivery purpose, although the viral vectors are highly efficient, they are limited to shRNA delivery and remain highly immunogenic and carcinogenic while the non-viral systems as promising alternatives for siRNA delivery are relatively safe and cost-effective. Being usually polycationic, they are able to form complexes with anionic siRNA, protecting it from nuclease attack and facilitating cellular uptake through electrostatic interactions with negatively charged plasma membrane or through specific interactions between the ligand anchored to the complex and the receptor on the cell membrane. ${ }^{8}$ Among the non-viral vectors, polyplexes and lipoplexes have been found efficient for siRNA delivery with significant gene silencing effect both in vitro and in vivo. However, synthetic non-viral systems are still inefficient with an increase in performance often being associated with an increase in cytotoxicity. ${ }^{10}$ The major obstacle for siRNA delivery in the non-viral route is the degradation of a significant portion of the internalized siRNA by nucleases. ${ }^{11}$

We have recently developed an efficient delivery system based on some fascinating properties of carbonate apatite- ability of preventing crystal growth for generation of nanoscale particles as needed for efficient endocytosis and fast dissolution kinetics in endosomal acidic compartments to facilitate the release of delivered therapeutics from the particles and endosomes. ${ }^{12-15}$ Here, we show that $\mathrm{pH}$ sensitive carbonate apatite particles having high affinity interactions with siRNAs, mediate efficient endocytosis and subsequent endosomal escape of the siRNAs, leading to the silencing of reporter gene expression more effectively than commercially available lipofectamine. Additionally, nanoparticle-assisted intracellular delivery of validated siRNA against cyclin B1 mRNA results in significant inhibition of cancer cell growth. Moreover, delivery of the anti-cyclin B1 siRNA sensitizes a human cervical cancer cell line (HeLa cell) to cisplatin and doxorubicin as well.

\section{Materials and Methods}

\section{Reagents}

Plasmid pGL3 (Promega) containing a luciferase gene under SV40 promoter and pEGFP-N2 (CLONTECH Laboratories, Inc.) containing green fluorescence protein gene under CMV were propagated in the bacterial strain XL-1 Blue and purified by QIAGEN plas- 
mid kits. LysoTrackerTM Red DND-99, MTT (3(4,5-Dimethylthiazol-2-yl) -2,5-diphenyl tetrazolium bromide) and DMEM were purchased from Molecular Probes, Sigma and Gibco BRL, respectively. The lipofectamine 2000 transfection reagent was obtained from Invitrogen ${ }^{\mathrm{TM}}$ corporation, California, USA. Luciferase GL3 siRNA (Target sequence 5'-AACTTACGCTGAGTACTTCGA-3'), GFP-22 siRNA (Target sequence 5'-CGGCAAGCTGACCCTGAAGTTC AT-3'), siRNA against cyclin B1 (Target sequence 5'-AACACTTATACTAAGCACCAA-3') and all Stars Neg. siRNA Fluorescein were purchased from QIAGEN. siRNAs were delivered in the lyophilized form and upon delivery the siRNAs were diluted to obtain a $20 \mu \mathrm{M}$ solution using RNAse-free water provided by Qiagen. The siRNA solution was then allocated into multiple reaction tubes for storage as repeated thawing might affect siRNA's silencing efficiency. The siRNAs were stored at $-20^{\circ} \mathrm{C}$ as recommended by Qiagen.

\section{Cell culture}

HeLa cells were cultured in $75-\mathrm{cm}^{2}$ flasks in Dulbecco's modified Eagle's medium (DMEM, Gibco BRL) supplemented with 10\% fetal bovine serum (FBS), $50 \mu \mathrm{g}$ penicillin $\mathrm{mL}^{-1}$, $50 \mu \mathrm{g}$ streptomycin $\mathrm{mL}^{-1}$ and $100 \mu \mathrm{g}$ neomycin $\mathrm{mL}^{-1}$ at $37^{\circ} \mathrm{C}$ in a humidified $5 \% \mathrm{CO}_{2}$-containing atmosphere.

\section{Formation of siRNA/carbonate apatite particles and transfection of cells}

Cells from the exponentially growth phase were seeded at 50,000 cells per well into 24well plates the day before transfection. $3-6 \mu \mathrm{L}$ of $1 \mathrm{M} \mathrm{CaCl}_{2}$ was mixed with $100 \mathrm{pM}-100 \mathrm{nM}$ of siRNA in $1 \mathrm{~mL}$ of fresh serum-free $\mathrm{HCO}_{3}-$ (44 $\mathrm{mM}$ )-buffered DMEM medium ( $\mathrm{pH} 7.5$ ), followed by incubation at $37^{\circ} \mathrm{C}$ for $30 \mathrm{~min}$ for complete generation of siRNA/carbonate apatite particles. Medium with generated siRNA-containing particles was added with $10 \%$ FBS to the rinsed cells. After $4 \mathrm{hr}$ incubation, the medium was generally replaced with serum-supplemented medium and the cells were cultured up to $24-72 \mathrm{~h}$ depending on the assay. In some experiments, siRNA/apatite particles were continuously incubated with the cells for $48 \mathrm{~h}$. siRNAlipofectamine formulation and transfection were done according to the procedure provided by Invitrogen.

\section{Determination of siRNA loading efficiency}

The amount of fluorescein-labeled siRNA adsorbed onto apatite nanoparticles was determined from the fluorescence intensity of the siRNA within the pellet obtained after centrifugation of siRNA/apatite complexes. Following generation of siRNA/apatite particles as described above, using $5 \mathrm{mM} \mathrm{Ca}^{2+}$ and 1-200 $\mathrm{nM}$ of fluorescein siRNA and centrifugation at $15000 \mathrm{rpm}$ for $3 \mathrm{~min}$, the resulting pellet was washed 3 times with the same medium and dissolved in $100 \mu \mathrm{L}$ of $10 \mathrm{mM}$ EDTA-PBS. The dissolved particle solution was taken to an assay plate and quantified for the fluorescence intensity by a fluorescence microplate reader. Free fluorescein-labeled siRNA (1pM to 200 $\mathrm{nM}$ ) in PBS was quantified and plotted to make the calibration curve with the help of which the actual siRNA loading was quantified.

\section{Intracellular localization of siRNAs with apatite nanoparticles}

HeLa cells were seeded at 15,000 cells per $\mathrm{cm}^{2}$ on $0.1 \%(\mathrm{w} / \mathrm{v})$ collagen-coated glass coverslips $(24 \times 24 \mathrm{~mm})$ on the day before intracellular delivery. Fluorescein siRNA/apatite nanoparticles were added onto HeLa cells in the same manner as mentioned above. After adding into the cells and removal of residual complexes at 1, 2 or $4 \mathrm{~h}$, endosomes and lysosomes were stained with LysoTracker ${ }^{\mathrm{TM}}$ Red DND-99 (Molecular Probes) according to the manufacturer's protocol and the cells were fixed with formaldehyde solution. Additionally, nuclei were stained with 4', 6-diamino-2phenylindole (DAPI) and observed with A1 confocal laser scanning microscope (Nikon, Tokyo, Japan).

\section{Gene silencing}

HeLa cells expressing GFP and luciferase were generated by transfection with plasmid DNA encoding GFP and luciferase using the apatite and the lipofectamine 2000 (according to the manufacturer's instructions). Briefly, cells were seeded on a 24 -well tissue culture plate at a density of $0.5 \times 10^{5}$ cells per well and incubated overnight in DMEM. On the day of transfection, the medium was removed and replaced with fresh media without serum. Apatite/luciferase plasmid or lipofectamine/ luciferase plasmid complexes were added onto the cells in each well and incubated for $4 \mathrm{~h}$. Media were then removed and the cells were washed with PBS, followed by replenishing fresh media containing serum. The cells were incubated for $24 \mathrm{~h}$ at $37{ }^{\circ} \mathrm{C}$ under C02 atmosphere. In the next day, $1 \mathrm{ml}$ of apatite or lipofectamine suspension prepared with $10 \sim 100 \mathrm{nM}$ of luciferase siRNA (as described before) was added to each well and incubated at $37^{\circ} \mathrm{C}$ under a $5 \% \mathrm{CO}_{2}$ atmosphere for $24 \mathrm{~h}$. Luciferase gene expression was monitored by using a commercial kit (Promega) and photon counting (TD-20/20 Luminometer, USA). Each transfection experiment was done in triplicate and transfection efficiency was expressed as mean light units per mg of cell protein.

In case of GFP plasmid co-transfection, $2 \mu \mathrm{g}$ of plasmid DNA and 100pM-100nM of GFP siRNA were used to prepare the DNA/siRNA complexes of apatite and lipofectamine, that were subsequently added onto the cells with either 10\% FBS (for apatite complexes) or no FBS (for lipofectamine complexes) for $4 \mathrm{hr}$ incubation. The medium was replaced by fresh DMEM with 10\% FBS and incubated for $72 \mathrm{~h}$.

In case of HeLa cells stably expressing GFP, the apatite/GFP siRNA or the lipofectamine/ GFP siRNA particle suspensions produced in the same way as described above, were added onto the cells and incubated for $72 \mathrm{~h}$. The cells were lysed using the lysis buffer (NP40) and the intracellular fluorescein intensity was determined using a microplate reader (DTX 880 , Multimode Detector by BECKMAN COULTER). In case of cyclin B1 siRNA delivery, apatite nanoparticles with cyclin B1 siRNA were incubated with HeLa cells continuously for $48 \mathrm{~h}$ either in presence or absence of cisplatin, doxorubicin and paclitaxel and the cellular toxicity level was assessed by 3-(4,5Dimethylthiazol-2-yl)-2,5-diphenyltetrazolium bromide (MTT) assay.

\section{Cell viability assessment with MTT assay}

$30 \mu \mathrm{L}$ of MTT solution $(5 \mathrm{mg} / \mathrm{mL})$ was added to each well after the specified periods of cell incubation (as mentioned in section 2.10), followed by incubation for $4 \mathrm{~h}$ at $37^{\circ} \mathrm{C} .0 .5 \mathrm{~mL}$ of DMSO was added after removal of media. After resolving crystals and incubating for $5 \mathrm{~min}$ at $37^{\circ} \mathrm{C}$, absorbance was measured in a microplate reader at $570 \mathrm{~nm}$ with a reference wavelength of $630 \mathrm{~nm}$. Cell viabilities were normalized to the absorbance of non-treated cells. MTT assay was also performed in a similar way after $48 \mathrm{~h}$ consecutive incubation of HeLa cells with cyclin B1 siRNA/apatite complexes.

\section{Results and Discussion}

\section{Assessment of binding affinity of siRNA to carbonate apatite}

Since siRNA is negatively charged owing to to its phosphate backbone while the carbonate apatite particles are positively charged due to the presence of calcium ions in the apatite structure, it was presumed that siRNA would bind to the apatite by ionic interactions. As shown in Figure 1, the binding affinity of siRNA to the apatite particles is increased almost propotionately with increasing concentrations of the available siRNA (1 to $100 \mathrm{nM}$ ) in the medium. A maximum binding of 50\% was achieved when the initial siRNA concentration was $100 \mathrm{nM}$. No further increase in the degree of siRNA binding was observed by increasing 
siRNA concentration to $200 \mathrm{nM}$, suggesting that the anion-binding sites $\left(\mathrm{Ca}^{2+}\right.$-rich domains) are saturated by complexation with siRNA molecules .

\section{Cellular uptake and endosomal escapes of siRNA carried by apatite nanoparticles}

Efficient delivery of siRNA to the cytosol of target cells depends on both the endocytosis of the non-viral vectors across the plasma membrane and their subsequent escape from endosomal/ysosomal compartments. A confocal microscopic analysis was performed on HeLa cells to observe the cellular localization of fluorescein siRNA in a time dependent manner from 1 to $4 \mathrm{~h}$ after the delivery of fluorescein siRNA/apatite complexes and staining of the endosomes/lysosomes with LysoTracker ${ }^{\mathrm{TM}}$ Red. As shown in Figure 2, most of the fluorescein siRNAs were co-localized in stained endosomes and/or lysosomes after $1 \mathrm{~h}$ incubation of HeLa cells with siRNA/apatite complexes.

However, after $2 \mathrm{~h}$ most of the siRNAs escaped the endocytic vesicles and following 4 $\mathrm{h}$, only a few dots of fluorescein siRNAs were still associated with the stained endo-lysosomes suggesting that the endosomal escape of siRNA was almost completed after $4 \mathrm{hr}$ incubation. The high dissolution rate of carbonate apatite particles might contribute to the destabilization of endosomes releasing siRNA to the cytoplasm, since v-ATPase-driven excessive proton transfer into the endosomes to dissolve the particles could cause passive chloride influx and create osmotic pressure across the endosomal membrane, leading to endosome swelling and rupture. ${ }^{12-15}$

\section{Estimation of gene silencing efficacy}

The final effect of siRNA on silencing gene expression depends on the integrity of the siRNA after release from the endosomes as well as from the particles. The efficiency of siRNA delivery was first assessed by cotransfection of GFP gene and siRNA in HeLa cells. The anti-GFP siRNAs were transfected at varied concentrations (from $100 \mathrm{pM}$ to $100 \mathrm{nM}$ ) along with GFP plasmids using apatite and silencing efficiency was compared with lipofectamine 2000 (Figure 3). At 100 pmol of siRNA, more than $80 \%$ silencing was achieved with apatite particles- a value significantly higher than that of lipofectamine 2000. With increasing siRNA concentration to $1 \mathrm{nM}$, the silencing efficiency for the apatite became almost $100 \%$ whereas to achieve the similar level of efficacy, lipofectamine required 10 time more concentration of the siRNA (i.e., 10 nM) (Figure 3a and b). We also investigated the silencing effects on transiently expressed reporter gene by sequentially trasfecting HeLa cells with luciferase gene (to express the luciferase mRNA and protein) and then, with luciferase siRNA to cleave the expressed mRNA. With 10 and $100 \mathrm{nM}$ of siRNA concentrations, almost $72 \%$ and $80 \%$ silencing were achieved, respectively, with carbonate apatite nanoparticles, that is highly comparable with lipofectamine 2000 (Figure 3c).

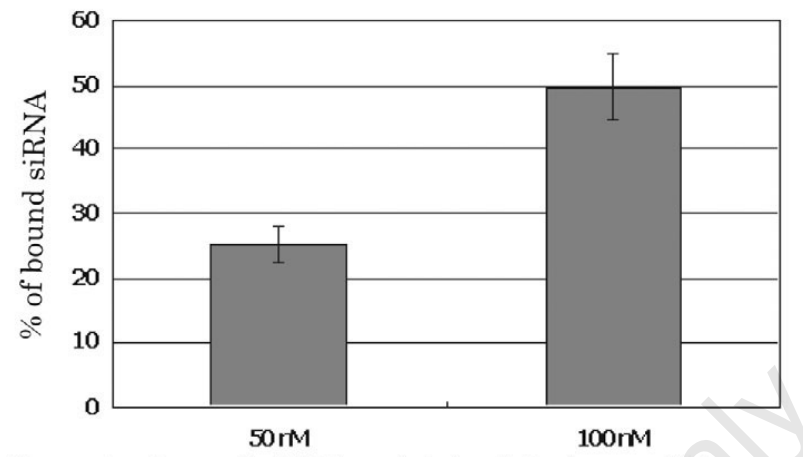

Concentrations of siRNA maintained during particle preparation
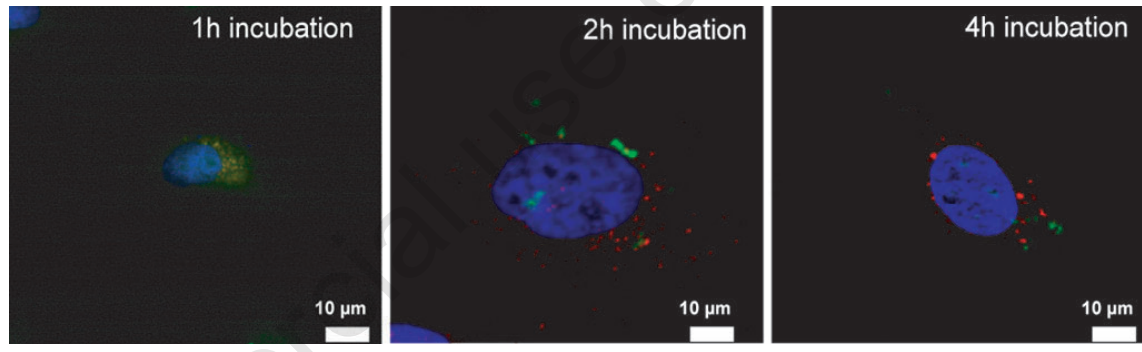

Figure 2. Endosomal escape of fluorescein siRNAs following endocytosis by apatite particles.

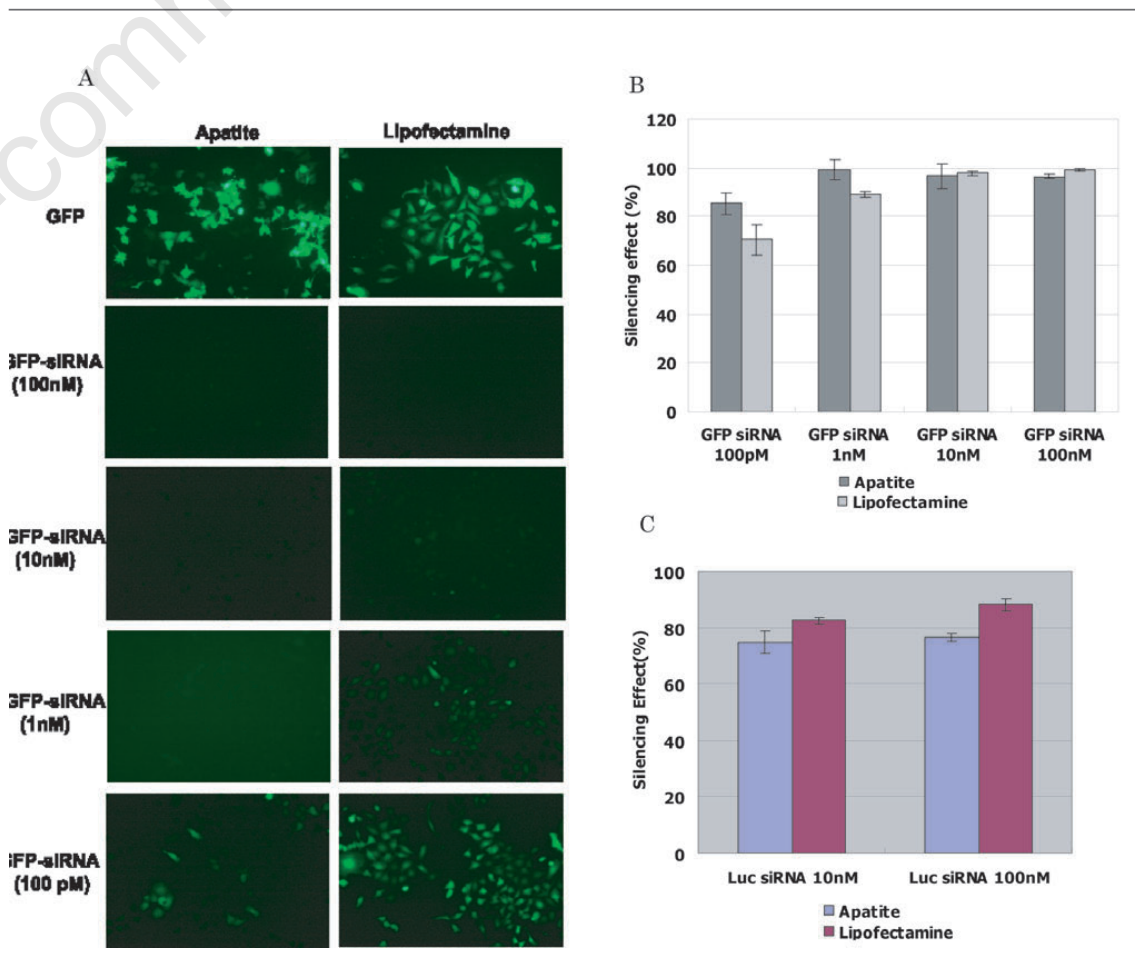

Figure 3. Silencing of GFP and luciferase expression, respectively, by siGFP and antiluciferase siRNA.
Figure 1. Binding affinity of siRNA to apatite particles.

\section{cell viability}

In order to evaluate cyclin B1 gene (CCNB1) ancer in cancer therapeutics, we carrier of anti-cyclin B1 siRNAs, since expression of cyclin B1 is essentially needed during 
the onset of mitosis and thus, knock-down of the gene might result in apoptosis of cancer cells. ${ }^{16}$ The apatite-siRNA complexes made using $10 \mathrm{nM}$ of pre-validated anti-cyclin B1 siRNA were used for transfection of HeLa cells for a consecutive period of $48 \mathrm{~h}$ prior to the assessment of cell viability by MTT assay. As shown in Figure 4, knockdown of cyclin B1 gene expression caused more than $25 \%$ of the cells to be killed in comparison to the nanoparticle-treated cells, suggesting that cyclin B1 is potentially a vital target for cancer therapy.

\section{Influences of cyclin B1 gene knock-} down on cisplatin-induced cell toxicity

Cisplatin is one of the most effective anticancer drugs for solid tumors, including ovarian, testicular, cervical, and small cell lung cancers. ${ }^{17,18}$ Treatment of HeLa cells with $1 \mu \mathrm{M}$ of cisplatin for 2 consecutive days caused $8 \%$ of cell death compared with particles only (Figure 5) while $32 \%$ of the cells were killed for the treatment where both apatite/siRNA complexes and cisplatin were incubated together with the cells for the same period of time. Since the combination of siRNA and cisplatin produced much better effects in cancer cell killing than either siRNA or drug only, we suggest that $1 \mu \mathrm{M}$ of cisplatin might induce expression of more cyclin $\mathrm{B} 1$ than the basal level ${ }^{19}$ in HeLa cells and therefore, silencing of cyclin B1 expression significantly perturbed cell growth by the dual effects of gene knockdown and drug action. On the contrary, the combined treatment with apatite/anti-cyclin B1 siRNA complex and a lower dose of cisplatin (200 nM) resulted in no further decrease in cell viability compared to siRNA or drug alone, suggesting that the concentration of the drug might be a determining factor in influencing the expression of cyclin B1.19,20

\section{Influences of cyclin B1 gene knock- down on doxorubicin-induced cell toxicity}

Doxorubicin is another chemotherapy drug widely used for the treatment of a variety of cancers including cervical cancer. ${ }^{21,22}$ Doxorubicin which killed $50 \%$ of the cells at 1 $\mu \mathrm{M}$ concentration of the drug (Figure 6) seems to be more potent than cisplatin which killed only $8 \%$ of the cells at the same dose (Figure 5)

following continuous 2 day incubation with HeLa cells. Silencing of cyclin B1 gene following intracellular delivery of apatite/anti-cyclin B1 siRNA, sensitized the cells to doxorubicin similarly like cisplatin at that particular concentration $(1 \mu \mathrm{M})$ killing more than $53 \%$ of the cells due to the synergistic effect of the drug and the gene knockdown. This could be due to the induction of cyclin B1 accumulation by doxorubicin stimulating the synthesis and inhibiting the degradation of cyclin $\mathrm{B}^{23}$ and consequently, its knockdown synergistically enhanced the cancer cell apoptosis in presence of doxorubicin.

The combined treatment with apatite/anticyclin B1 siRNA complex and a lower dose of doxorubicin $(200 \mathrm{nM})$ demonstrated no further decrease in cell viability compared to siRNA or drug alone, suggesting that the lower concentration of doxorubicin might not have increased intracellular cyclin B1 levels or induced senescence sensitizing the cells to apoptosis. $^{24}$

\section{Influences of cyclin B1 gene knock- down on paclitaxel-induced cell toxicity}

Paclitaxel as a microtubule stabilizer is used for the treatment for various cancers including
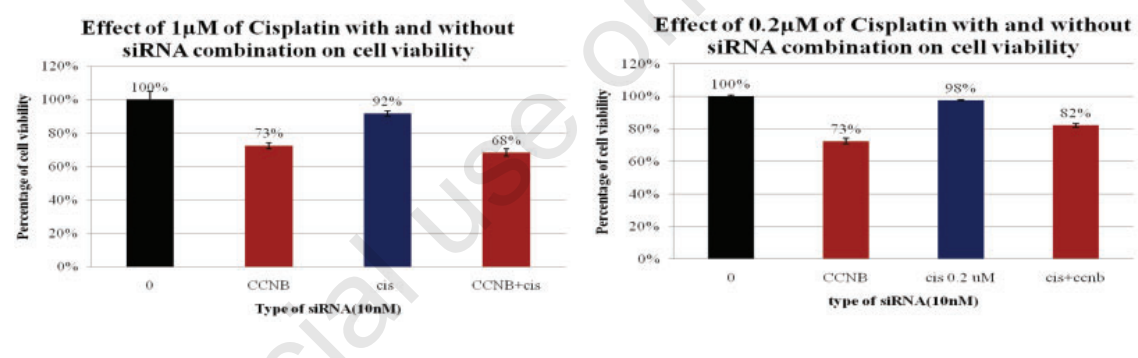

Figure 5. Effects of silencing cyclin B1 expression on viability of cancer cells under higher (left side) and lower doses (right side) of cisplatin.
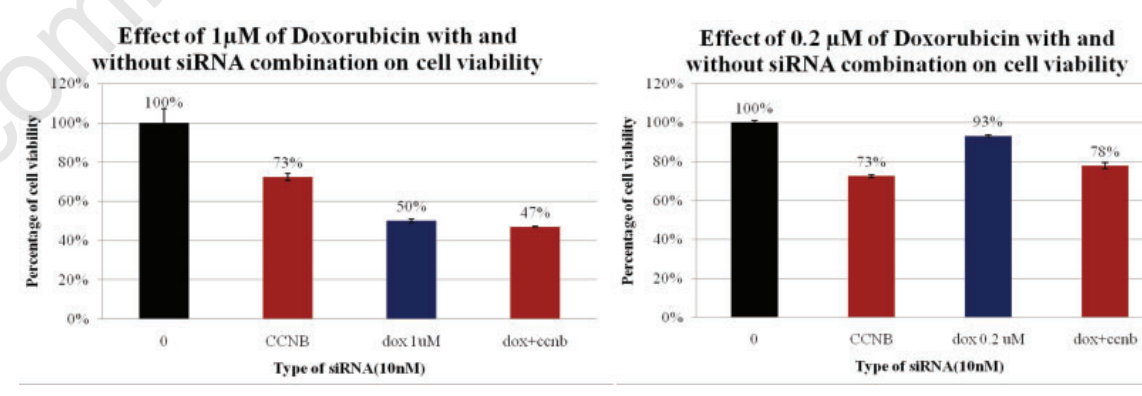

Figure 6. Effects of silencing cyclin B1 expression on viability of cancer cells under higher (left side) and lower doses (right side) of doxorubicin.
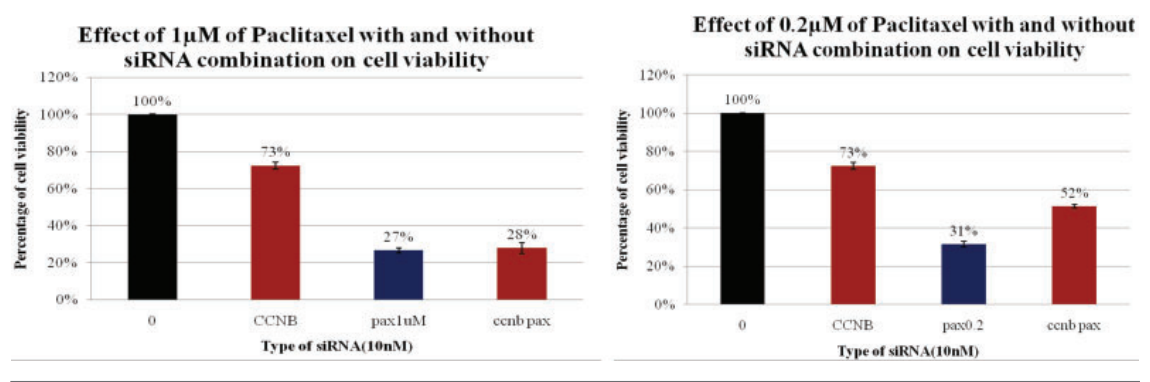

Figure 7. Effects of silencing cyclin B1 expression on viability of cancer cells under higher (left side) and lower doses (right side) of paclitaxel. 
of the cells to death, indicating that paclitaxel was most effective among the drugs used in the study. Treatment with both anti-cyclin B1 siRNA and paclitaxel killed $72 \%$ of the cells, whcih was higher than the effectiveness of the siRNA alone, but almost similar to that of paclitaxel alone which killed $73 \%$ of the cells. Although paclitaxel might increase cellular cyclin B1 level, ${ }^{27}$ the hight cytoxicity of paclitaxel had the diminating role over the geneknockdown in killing the cancer cells. Similar findings were obtained in presence of $0.2 \mu \mathrm{M}$ doxorubicin which killed almost same number of cells as $1 \mu \mathrm{M}$ of the drug.

We have developed an intracellular siRNA delivery system based on $\mathrm{pH}$ sensitive carbonate apatite nanoparticles taking the advantages of endocytosis-mediated siRNA entry and its subsequent escape from the endocytic vesicle. The interesting effects of carbonate apatite-facilitated konckdown of cyclin B1 in combination with three popular anti-cancer drugs in inducing apoptosis of cervical cancer cells would obviously inspire more studies to be carried out in other cancer cell lines and various animal models of cancers .

\section{References}

1. Winkler J, Martin-Killias P, Plückthun A, et al. EpCAM-targeted delivery of nanocomplexed siRNA to tumor cells with designed ankyrin repeat proteins. Mol Cancer Ther 2009;8:2674-83.

2. de Fougerolles AR. Delivery vehicles for small interfering RNA in vivo. Hum Gene Ther 2008;19:125-32.

3. Gao K, Huang L. Nonviral methods for siRNA delivery. Mol Pharm 2009;6:651-8.

4. Lee NS, Rossi JJ. Control of HIV-1 replication by RNA interference. Virus Res 2004; 102:53-8.

5. Grünweller A, Hartmann RK. RNA interference as a gene-specific approach for molecular medicine. Curr Med Chem 2005;12:3143-61.

6. Ito M, Kawano $\mathrm{K}$, Miyagishi $\mathrm{M}$, et al. Genome-wide application of RNAi to the discovery of potential drug targets. FEBS Lett 2005;579:5988-95.

7. Lu PY, Xie F, Woodle MC. In vivo application of RNA interference: from functional genomics to therapeutics. Adv Genet 2005; 54:117-42.

8. Chowdhury EH. Nuclear targeting of viral and non-viral DNA. Expert Opin Drug Deliv 2009;6:697-703.

9. Reischl D, Zimmer A. Drug delivery of siRNA therapeutics: potentials and limits of nanosystems. Nanomedicine 2009;5:820.

10. Luo D, Saltzman WM. Synthetic DNA delivery systems. Nat Biotechnol 2000;18:33-7.

11. Ganta S, Devalapally H, Shahiwala A, et al. A review of stimuli-responsive nanocarriers for drug and gene delivery. J Control Release 2008;126:187-204.

12. Chowdhury EH, Akaike T. pH-sensitive inorganic nano-particles and their precise cell targetibility: An efficient gene delivery and expression system. Curr Chem Biol 2007;1:201-13.

13. Chowdhury EH, Akaike T. High performance DNA nano-carriers of carbonate apatite: multiple factors in regulation of particle synthesis and transfection efficiency. Int J Nanomedicine 2007;2:101-6.

14. Chowdhury EH. Self-assembly of DNA and cell-adhesive proteins onto $\mathrm{pH}$-sensitive inorganic crystals for precise and efficient transgene delivery. Curr Pharm Des 2008; 14:2212-28.

15. Chowdhury EH, Akaike T. Bio-functional inorganic materials: An attractive branch of gene-based nano-medicine delivery for 21st century. Curr Gene Ther 2005;5:66976 .

16. Egloff AM, Vella LA, Finn OJ. Cyclin B1 and other cyclins as tumor antigens in immunosurveillance and immunotherapy of cancer. Cancer Res 2006;66:6-9.

17. Eastman A. Activation of programmed cell death by anticancer agents: cisplatin as a model system. Cancer Cell 1990;2:275-9.

18. Alberts DS, Garcia D, Mason-Liddil N. Cisplatin in advanced cancer of the cervix: an update. Semin Oncol 1991;18:11-24.

19. Links M, Ribeiro J, Jackson P, et al. Regulation and deregulation of G2 checkpoint proteins with cisplatin. Anticancer Res 1998;18:4057-66.

20. Kim KC, Jung CS, Choi KH. Overexpression of p73 enhances cisplatininduced apoptosis in HeLa cells. Arch Pharm Res 2006;29:152-8.

21. Kristensen G, Tropé C. Endometrial cancer: the management of high-risk disease. Curr Oncol Rep 2004;6:471-5.

22. Nguyen HN, Nordqvist SR. Chemotherapy of advanced and recurrent cervical carcinoma. Semin Surg Oncol 1999;16:247-50.

23. Ling $\mathrm{YH}$, el-Naggar AK, Priebe W, et al. Cell cycle-dependent cytotoxicity, G2/M phase arrest, and disruption of p34cdc2/cyclin B1 activity induced by doxorubicin in synchronized P388 cells. Mol Pharmacol 1996; 49:832-41.

24. Sliwinska MA, Mosieniak G, Wolanin K, et al. Induction of senescence with doxorubicin leads to increased genomic instability of HCT116 cells. Mech Ageing Dev 2009; 130:24-32.

25. De Vincenzo R, Amadio G, Ricci C, et al. Treatment of cervical cancer in Italy: strategies and their impact on the women. Vaccine 2009;27:A39-45.

26. Pectasides D, Kamposioras K, Papaxoinis G, et al. Chemotherapy for recurrent cervical cancer. Cancer Treat Rev 2008;34:60313.

27. Ling $\mathrm{YH}$, Consoli U, Tornos C, et al. Accumulation of cyclin B1, activation of cyclin B1-dependent kinase and induction of programmed cell death in human epidermoid carcinoma KB cells treated with taxol. Int J cancer 1998;75:925-32. 